Supplementary Information for:

\title{
Critical Packing Density of Water-Mediated Nonstick Self-Assembled Monolayer Coatings
}

Hsieh Chen*

Aramco Americas: Aramco Research Center-Boston, Cambridge, MA 02139, USA

*hsieh.chen@aramcoamericas.com 


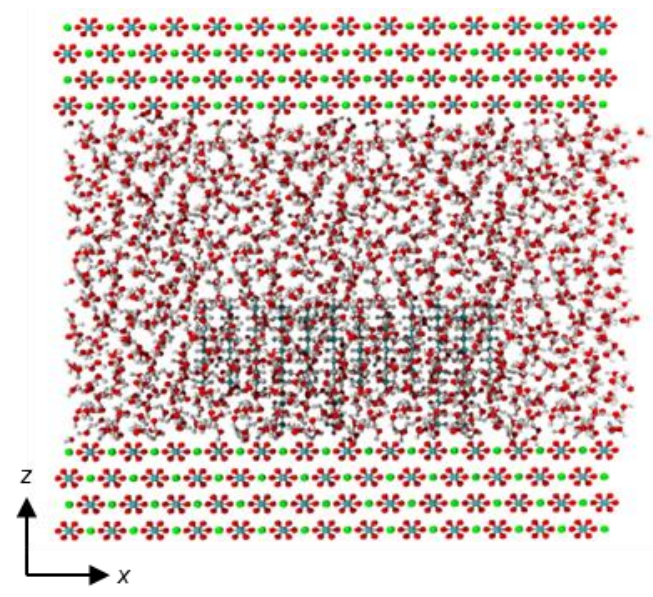

Fig. S1. Snapshot of initial simulation box the same as in Fig. $1 \mathrm{~b}$ but with water molecules also shown. The atom colors are: $\mathrm{C}=$ cyan, $\mathrm{O}=$ red, $\mathrm{Ca}=$ green, and $\mathrm{F}=$ pink. 
$d=2.7 \mathrm{~nm}$

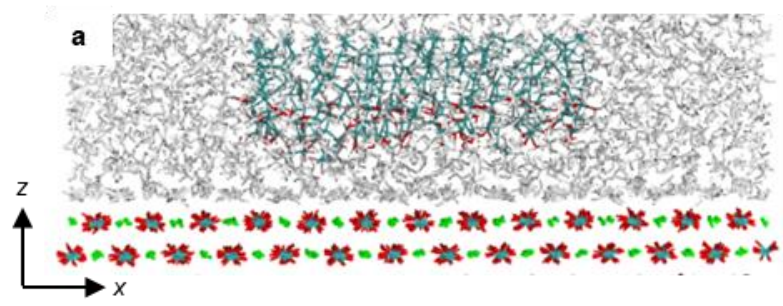

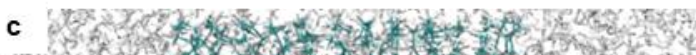

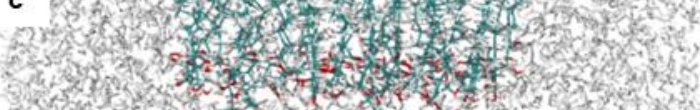

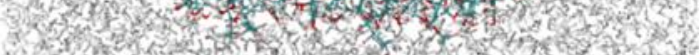

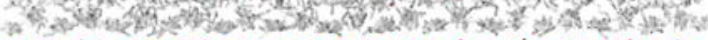

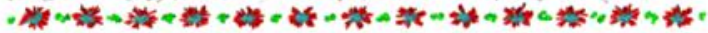

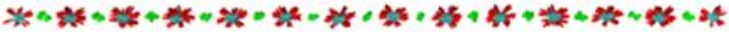
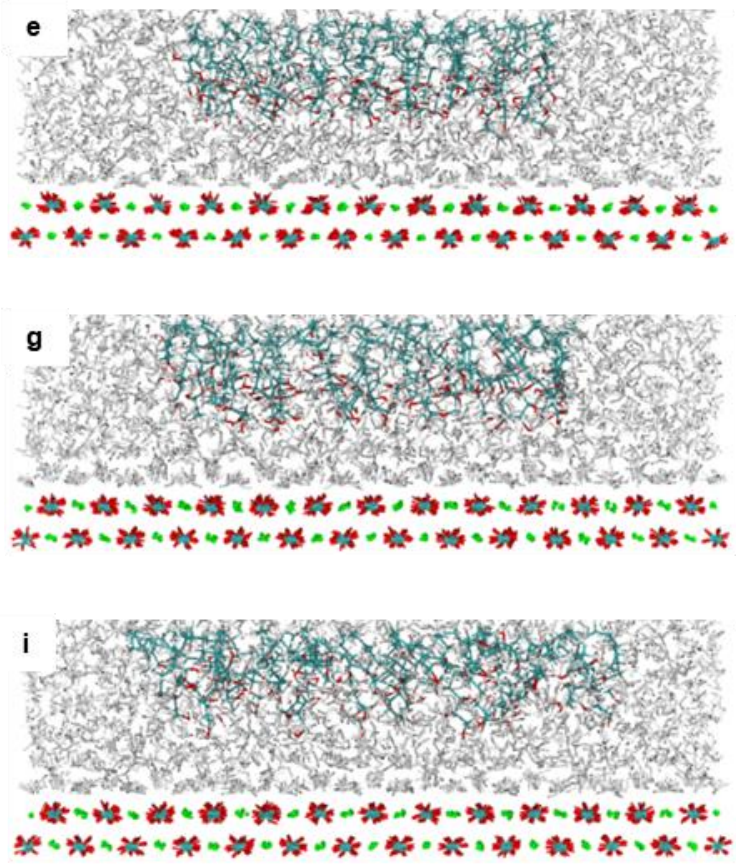

$d=2.26 \mathrm{~nm}$
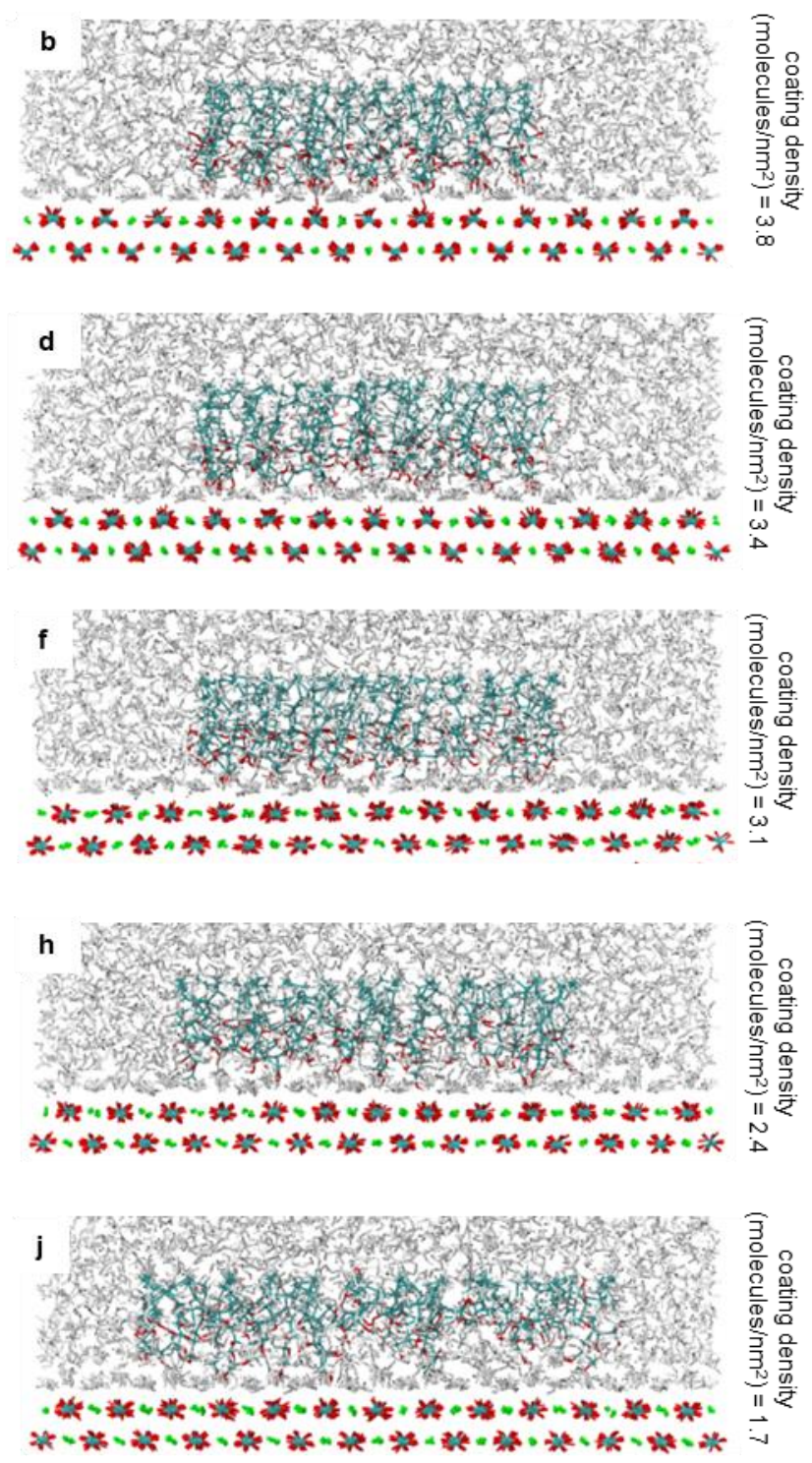

Fig. S2. Simulation snapshots of C8OH3-C2F10 SAM with $10 \%$ C2F10 with coating densities (a and b) 3.8, (c and d) 3.4, (e and f) 3.1, (g and h) 2.4, and (i and j) 1.7 molecules/nm ${ }^{2}$ before $(d=2.7 \mathrm{~nm}$; a, c, e, g, and i) and during SAM-calcite interactions $(d=2.26 \mathrm{~nm} ; \mathrm{b}, \mathrm{d}, \mathrm{f}, \mathrm{h}$, and $\mathrm{j})$. The atom colors of SAM and calcite are the same as in Fig. S1. The water molecules are shown in light gray. 

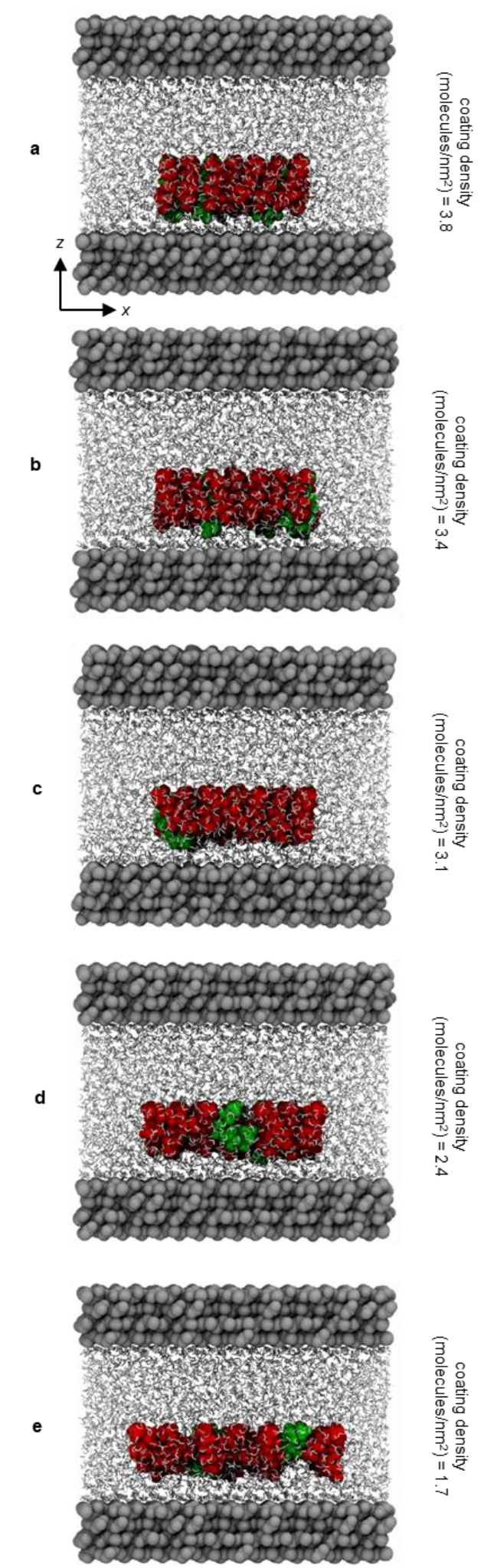

Fig. S3. Simulation snapshots the same as in Fig. 4b, d, f, h, and j but with calcite and water molecules also shown. The $\mathrm{C} 8 \mathrm{OH} 3, \mathrm{C} 2 \mathrm{~F} 10$, calcite, and water molecules are shown in red, green, dark gray, and light gray. 